\title{
Режимы самосканирования в тулиевом волоконном самосканирующем лазере
}

\author{
А.Е. Бударных", И.А. Лобач, С.И. Каблуков \\ Институт автоматики и электрометрии СО РАН \\ *E-mail: buar.work@gmail.com
}

DOI: 10.31868/RFL2020.191-192

Исследование лазеров с эффектом самоиндуцированного сканирования (для простоты, самосканирования) длины волны является одним из бурноразвивающихся направлений в волоконной оптике [1]. Благодаря простоте схемы, самосканирующие лазеры способны составить серьезную конкуренцию традиционным перестраиваемым лазерам на основе перестраиваемых элементов, таких как дифракционные решетки или призмы. В недавних работах был продемонстрирован самосканирующий тулиевый волоконный лазер с генерацией в области 1.9 мкм [2-3]. Отличительной особенностью такого лазера стала разнообразная спектральная динамика: было получено прямое и обратное сканирование (периодическое увеличение и уменьшение длины волны, соответственно) и режим с остановкой сканирования [3]. При этом смена между режимами осуществлялась подстройкой мощности лазера накачки. Хотя смешанные режимы достигались и раньше, подобное сочетание режимов было обнаружено только в тулиевом самосканирующем лазере. Одним из возможных механизмов такого поведения в работе [3] было названо влияние амплитудных решеток поглощения. В ряде работ показано [4], что подобные структуры могут приводить к стабилизации длины волны генерации. В этом случае, может происходить конкуренция между процессами, вынуждающими к изменению длины волны (решетка усиления) и способствующие ее стабилизации (решетка поглощения). Для проверки этой гипотезы в работы было проведено детальное экспериментальное исследование влияния параметров схемы (длина активного волокна, длина волны лазера накачки), связанных с решетками поглощения, на характеристики эффекта самосканирования.

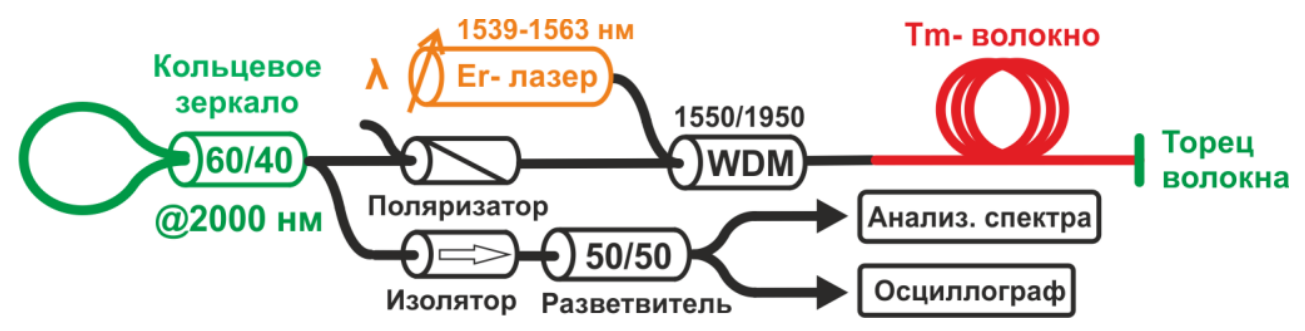

Рис. 1. Схема тулиевого самосканирующего лазера

Схема лазера (Рис.1) аналогична схеме из работы [3]. Принципиальное отличие заключается в использовании перестраиваемого лазерного источника с диапазоном перестройки в области 1539-1563 нм и максимальной выходной мощностью 0.66 Вт в качестве лазера накачки. Длина активного тулиевого волокна (Nufern PM TSF 9/125) варьировалась от 3.5 до 5.8 м. Режимы сканирования анализировались как по динамике интенсивности (с помощью фотодетектора Thorlabs DET10D/M и осциллографа LeCroy WavePro 725Zi-A), так и по динамике длины волны генерации (с помощью измерителя длин волн HighFinesse WS5). Для примера, приведем результаты по анализу направления и скорости перестройки длины волны. Измерения спектральной динамики проводились при раз- 
ных мощностях (от 420 до 660 мВт) и длинах волн (1540-1564 нм) накачки. Характерный график зависимости скорости сканирования от параметров накачки представлен на Рис.2. По горизонтальной оси отложены длина волны лазера накачки, а по вертикальной - мощность лазера накачки. Цветом отражается скорость сканирования: зеленому цвету соответствует положительная скорость и, следовательно, область прямого сканирования, синему цвету - отрицательная скорость и область обратного сканирования, штрихованная зона - область почти нулевого сканирования (модуль скорости менее 0.05 нм/сек). Также, стоит отметить, что были обнаружены примеры спектральных динамик, ранее не наблюдавшихся в тулиевом самосканирующем лазере.

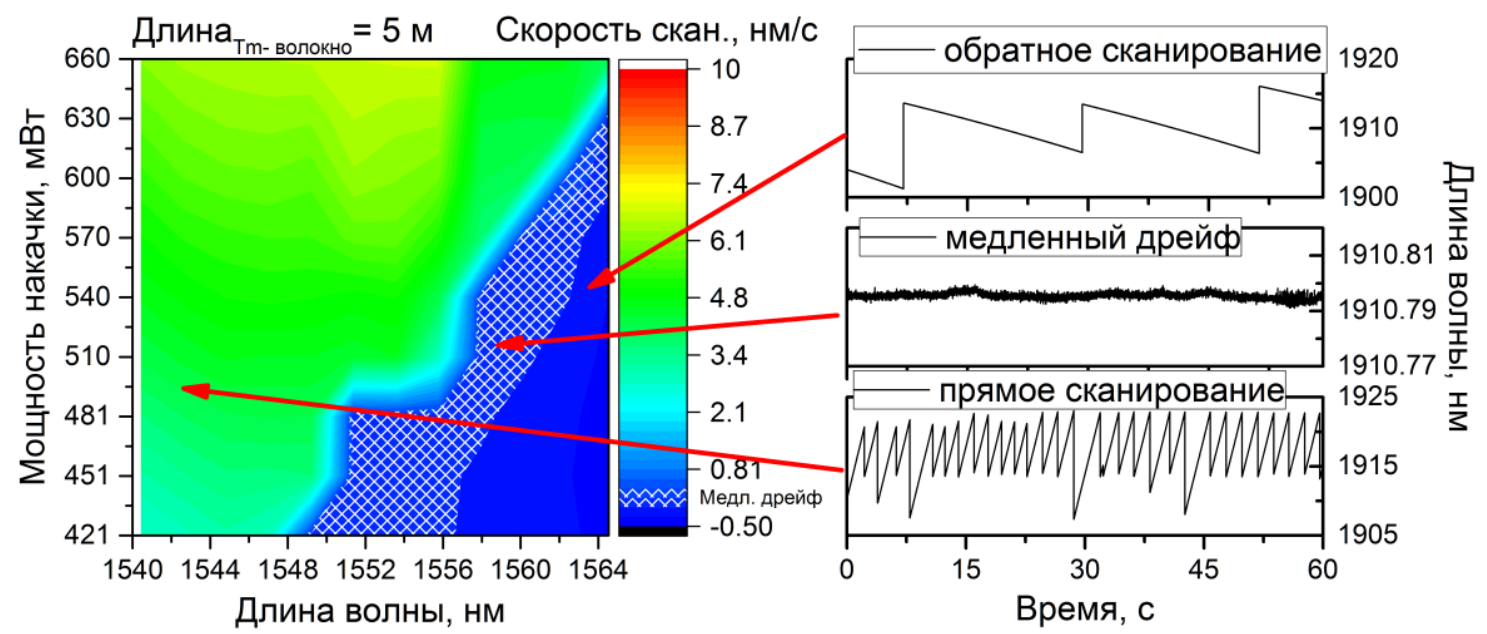

Рис. 2. Слева: зависимость скорости сканирования от длины волны излучения и мощности лазера при длине активного волокна 5 м. Справа: примеры режимов самосканирования для указанных областей.

График на Рис.2 соответствует схеме с активным волокном длиной 5 метров. Подобные зависимости были также получены и для активных волокон с длиной 3.5, 4.5 и 5.8 метров. Результаты экспериментов показывают, что при регулировании мощности имеется область критических значений, при которых происходит переход между обратным и прямым режимами сканирования. Было установлено, что среднее значение критической мощности увеличивается как с длиной волны лазера накачки, так и с увеличением длины активного волокна. Полученные результаты подтверждают гипотезу о влиянии динамических решеток поглощения. В частности, при увеличении мощности и/или длины волны накачки их влияние уменьшается, так как активное волокно прокачивается более однородно по длине. Ожидается, что эти результаты помогут в прогнозировании и оптимизации выходных характеристик в волоконном лазере с самосканированием длины волны. Информация о полученных результатах будет представлена более подробно в докладе.

Данная работа выполнена в рамках проекта РФФИ № 20-32-70058.

\section{Литература}

[1] I.A. Lobach, S.I. Kablukov et al, Opt. Express 19, 17632-17640 (2011)

[2] A.E. Budarnykh, A.D. Vladimirskaya et al, Opt. letters 43, 5307-5310 (2018)

[3] A.E. Budarnykh, I.A. Lobach, and S.I. Kablukov, Laser Physics Letters 16, 025108 (2019)

[4] J. Chen, Y. Zhao et al, IEEE Photonics Technology Letters 29, 439-441 (2017) 